\title{
LA LITERATURA INFANTIL Y JUVENIL ARGENTINA EN LAS CLASES DE ESPAÑOL COMO LENGUA EXTRANJERA. UNA PROPUESTA PARA LA REFLEXIÓN METALINGÜÍSTICA
}

\section{A LITERATURA INFANTIL E DA JUVENTUDE ARGENTINA NAS CLASSES ESPANHOLAS COMO LÍNGUA ESTRANGEIRA. UMA PROPOSTA DE REFLEXÃO METALINGUÍSTICA}

\author{
THE INFANT AND YOUTH LITERATURE ARGENTINA IN THE \\ SPANISH CLASSES AS A FOREIGN LANGUAGE. A PROPOSAL \\ FOR METALINGUISTIC REFLECTION
}

Resumen: El presente artículo plantea el abordaje de la literatura infantil y juvenil (LIJ) argentina en las clases de español como lengua extranjera. En el marco del Análisis del Discurso, en general, y la Polifonía Enunciativa, en particular, este trabajo propone indagar la literatura en su dimensión estética y en tanto forma de conocimiento, prestando atención a que su tratamiento privilegie el disfrute y la reflexión metalingüística (DI TULLIO, 2012 y XXX 2018), sin transformarse en una mera excusa para la enseñanza gramatical y la extracción de contenidos. En primer lugar, se caracteriza el uso del texto literario como herramienta didáctica en las clases de español como lengua extranjera y se explica el enfoque adoptado. En segundo lugar, se realiza un recorrido por la LIJ argentina y se ofrecen criterios para la selección de los materiales. Finalmente, se exponen diferentes aspectos para el abordaje de un texto específico de LIJ.

Palabras claves: Literatura infantil y juvenil. Argentina. Español. Discurso. Lengua extranjera.

Resumo: Este artigo apresenta a abordagem da literatura infantil argentina em espanhol como língua estrangeira. No âmbito da Análise do Discurso, em geral, e da Polifonia Enunciativa, em particular, este trabalho propõe investigar a literatura, em sua dimensão estética e como forma de conhecimento, atentando-se ao seu tratamento privilegiando o prazer e a reflexão metalinguística (DI TULLIO, 2012 e XXX 2018), sem se tornar uma mera desculpa para o ensino de gramática e extração de conteúdo. Em primeiro lugar, o uso do texto literário como ferramenta didática no espanhol como língua estrangeira é caracterizado e a abordagem adotada é explicada. Em segundo lugar, há uma turnê do LIJ argentino e os critérios para a seleção de materiais são oferecidos. Por fim, diferentes aspectos são apresentados para a abordagem de um texto específico da LIJ.

Palavras-chave: Literatura infantil e juvenil. Argentina. Espanhol. Discurso. Língua estrangeira

\begin{abstract}
This article presents the approach of Argentinean children's literature (LIJ) in Spanish as a foreign language. Within the framework of Discourse Analysis, in general, and the Enunciative Polyphony, in particular, this work proposes to investigate literature, in its aesthetic dimension and as a form of knowledge, paying attention to its treatment privileging metalinguistic enjoyment and reflection (DI TULLIO, 2012 and XXX 2018), without becoming a mere excuse for the teaching of grammar and content extraction. In the first place, the use of the literary text as a didactic tool in the Spanish as a foreign language classes is characterized and the adopted approach is explained. Second, there is a tour of the Argentine LIJ and criteria for the selection of materials are offered. Finally, different aspects are presented for the approach of a specific text of LIJ.
\end{abstract}

Keywords: Children and youth literature. Argentina. Spanish. Speech. Foreign Language

${ }^{1}$ Doctora en Lingüística, magíster en análisis de del Discurso, profesora y licenciada en Letras (Universidad de Buenos Aires), se desempeña actualmente como investigadora adjunta en Conicet y docente de Corrección de Estilo (Universidad de Buenos Aires)malencalfu@yahoo.com.ar 


\section{Introducción}

Gran cantidad de la bibliografía actual coincide en la relevancia de utilizar textos literarios como instrumentos didácticos en las clases de español como lengua extranjera. No obstante, el uso de literatura en español puede representar un gran desafío para el (futuro) docente y desencadenar una serie de dificultades y conflictos en la práctica concreta. Atento a ello, el presente artículo propone la reflexión sobre la función de la lectura literaria en las clases de ELSE, haciendo especial hincapié en los distintos aspectos didácticos implicados, como el enfoque a adoptar, la elección del material y la finalidad de la lectura.

Este trabajo, que se inserta en un proyecto de investigación mayor -radicado en el Consejo Nacional de Investigaciones Científicas y Técnicas (Argentina) y que indaga las propiedades discursivas de géneros editoriales con destinatario infantil, como el libro didáctico y la literatura infantil y juvenil, y su relación con las políticas editoriales-, se basa en una experiencia realizada en Brasil con futuros profesores de español. Vale aclarar que en 2013 inicié la vinculación académica con el "Programa en Estudios del Lenguaje", del Instituto de Lenguas Extranjeras del Instituto de Letras de la Universidad Federal Fluminense (UFF, Niterói, Río de Janeiro, Brasil) ${ }^{2}$, donde fui convocada con el fín de acercar a los estudiantes de grado a la literatura infantil y juvenil (de ahora en más LIJ) argentina y plantear su abordaje en las clases de ELSE. Dicha propuesta constituyó un gran desafío para mí, ya que se trataba de un público que, en líneas generales, desconocía la LIJ argentina y no eran lectores expertos de literatura en español. Esto me llevó a realizar una investigación exhaustiva sobre el campo y realizar una cuidadosa selección del corpus, atendiendo a las características específicas del grupo. Mi interés consistía en proponer un abordaje de los textos literarios de LIJ apelando a la reflexión metalingüística (DI TULLIO 2012 y XXX, 2018), en el marco del Análisis del Discurso, en general, y de la Polifonía enunciativa (ANSCOMBRE y DUCROT, 1984 y AUTHIER-REVUZ, 1984 y 1995), en particular. A partir de dicho encuadre, mi proyecto, en líneas generales, buscó abordar la literatura desde su plurisignificatividad y como forma de conocimiento (ISER, 1976), prestando especial a que su tratamiento privilegie el disfrute estético y la reflexión lingüística, pero sin transformarse en una mera excusa para la enseñanza de la gramática.

La transferencia del proyecto constó de dos talleres presenciales, dictados en 2013 y 2014 en la UFF, y de una producción de materiales de trabajo que compartí en forma digital con los estudiantes y docentes del programa, que utilizaron, al menos, hasta 2018. Sobre la base de un trabajo anterior $(\mathrm{XXX}, 2018)^{3}$, en esta oportunidad muestro otro segmento de la investigación, centrado en el abordaje de un texto de LIJ, "Mamá, ¿por qué nadie es como nosotros?", del escritor argentino Luis María Pescetti, editado por Alfaguara en 2005 dentro del libro Nadie te creería; reeditado por el Ministerio de Educación,

\footnotetext{
2 Agradezco especialmente a los Dres. María del Carmen Dahler y a Xoan Lagares, responsables del programa, por permitirme participar en ese espacio y desarrollar la transferencia de mi investigación.

${ }^{3}$ En un texto anterior, desarrollé una propuesta didáctica para aplicar en las clases de español como lengua extranjera, a partir de la experiencia en la UFF ya referida. Por un lado, planteé cómo encarar el trabajo de reflexión metalingüística en una serie de textos de LIJ correspondientes al género libro-álbum y, por el otro, propuse el diseño de proyectos de lectura y escritura. Para consultar este trabajo, ver XXX (2018).
} 
Ciencia y Tecnología en formato digital, en 2006; y, posteriormente por Santillana en formato libro impreso, en $2015^{4}$.

En lo que sigue, primero caracterizo el texto literario como herramienta didáctica en las clases de español como lengua extranjera y fijo el enfoque adoptado (\$2), luego realizo un sucinto recorrido por la LIJ argentina y doy cuenta de algunos criterios para la selección de los materiales (\$3), y explico diferentes aspectos para el abordaje de un texto literario (§4). Finalmente, muestro las conclusiones obtenidas (§5).

\section{El texto literario y la reflexión sobre el lenguaje}

Como se sabe, el texto literario ha sido una de las herramientas didácticas predilectas en el ámbito de la enseñanza de las lenguas. Si bien tuvo períodos de apogeo y otros en los que quedó relegado ${ }^{5}$, fue hacia la década de 1970 cuando volvió a cobrar protagonismo en las aulas con el avance del método comunicativo, que prestaba especial interés al estudio de la lengua en uso y valoraba el texto original dentro de su contexto de producción y circulación. Es así que, desde tal perspectiva, "el alumno se presenta como un individuo integrante de una sociedad en la que tiene que llevar a cabo múltiples acciones para conseguir determinados resultados, para ello deberá poner en práctica toda una serie de competencias" (LÓPEZ PRATS, 2009, p. 18).

Sin dudas, el empleo de materiales literarios presenta múltiples ventajas, por ejemplo, se trata de textos auténticos ${ }^{6}$ que brindan amplias posibilidades didácticas, de reflexión y de interpretación para los estudiantes. No obstante sus aspectos positivos insoslayables, algunos especialistas cuestionan su uso. Por ejemplo, Castro y Contreras (2011), basándose en su experiencia docente, advierten:

muchas veces la lectura de textos literarios puede ser contraproducente debido a que los estudiantes sienten frustración ante la imposibilidad de comprender en su totalidad los textos porque saben que la riqueza de la literatura está en poder "desmenuzar" los sentidos subyacentes. Por otra parte muchas veces se sostiene la brevedad como sinónimo de sencillez - por ejemplo: microcuentos, haikus y poesía en general-, entonces se eligen textos breves en los que habitualmente lo no dicho complejiza de manera excesiva el texto para un hablante no nativo, cuestión que profundiza el sentimiento de frustración. A lo largo de estos tres años hemos observado que la mayoría de nuestros estudiantes buscan siempre un

\footnotetext{
${ }^{4}$ Luis María Pescetti nació en San Jorge, Santa Fe (Argentina). Es escritor, actor y músico. Conduce programas radiales y actúa en espectáculos para niños. Ha realizado discos con canciones infantiles humorísticas: El vampiro negro, Cassete pirata y Antología de Luis Pescetti. Entre los premios internacionales que ha recibido por sus obras, se encuentran The White Ravens, que obtuvo en dos oportunidades, los destacados de ALIJA, el premio Casa de las Américas y el premio Fantasía. Su amplia producción de libros para niños es reconocida en Latinoamérica y España.

${ }^{5}$ El método de enseñanza dominante durante los años cincuenta y sesenta era el denominado "audiolingualismo".

6 No obstante, según López Prats (2009), ha habido tendencias a "adulterar" los textos para hacer las adaptaciones de nivel necesarias, lo cual provoca construcciones lingüísticas forzadas y da como resultado textos quiméricos por lo que respecta a la L1. Es decir, "se ha considerado el lenguaje literario como un aspecto negativo en la comunicación cotidiana de las personas, olvidando que la lengua es un continuum y que la literatura no es más que un uso de los varios que se dan en ese continuum" (LÓPEZ PRATS, 2009, p. 7)
} 
sentido ulterior (al modo de una moraleja) en la literatura que leemos en los cursos y, muchas veces, les parece un sinsentido la lectura de una obra que no lo presenta de una manera evidente (CASTRO Y CONTRERAS, 2011, p. 2).

En referencia al planteo de Castro y Contreras, es necesario tener en cuenta que la selección del material y los objetivos de lectura son claves para poder lograr una lectura literaria placentera. Explicitar dichos aspectos, así como la concepción de literatura que se enseña es vital para sortear experiencias desfavorables y evitar frustraciones en los estudiantes y docentes. Tal como sostiene Mendoza (2001, p. 55): "Conviene sustituir la idea de 'enseñar literatura' por otra idea, más amplia, que se centre en la idea de 'enseñar a apreciar la literatura' recobrando el sentido de disfrutar y valorar la obra literaria".

Llegados a este punto, vale aclarar que leer por placer no significa necesariamente una práctica que se construya sin teoría. Como afirma Bombini (1996): "En los últimos años, las lecturas simplificadoras de ciertas posiciones barthesianas sobre todo tomadas de su trabajo El placer del texto han venido a proponer una práctica de la lectura escolar que busca debilitar cualquier discurso sobre la literatura en pos de incentivar una relación'ingenua' - de lectura" (BOMBINI, 1996, p. 3)". Por el contrario, Bombini explica que no hay que pensar que la teoría constituye un obstáculo para la recepción "directa" de los textos, sino que puede constituir una forma acercamiento entre los alumnos y la literatura. En efecto, es imprescindible, brindarles a los estudiantes la posibilidad de acceder a un texto literario y de asirlo de estrategias y herramientas de lectura.

Con relación a ello, son variadas las metodologías para la enseñanza del español como lengua extranjera y, en concomitancia, existen diversas formas de abordar los textos de literatura en las clases de ELSE, como, por ejemplo, el enfoque gramatical, el estructural-funcional (a través de la búsqueda de contenidos) y por tareas. No obstante, cualquiera de estas perspectivas puede implicar un trabajo reduccionista del texto literario.

Recordemos la advertencia de Petit:

Escuchando a los lectores recordamos que el lenguaje no puede ser reducido a un código, a una herramienta de comunicación, a un simple vehículo de informaciones. El lenguaje nos construye. Cuanto más capaces somos de darle un nombre a lo que vivimos, a las pruebas que soportamos, más aptos somos para vivir y tomar cierta distancia de lo que vivimos, y más aptos seremos para construirnos en sujetos de nuestro propio destino (PETIT, 2001, p, 12).

Sin dudas, es vital abordar los textos con un espíritu interdisciplinario en el que se apliquen contenidos comunicacionales y lingüísticos, se trabaje la reflexión sobre el lenguaje y que también converjan herramientas de diferentes campos disciplinarios, como por ejemplo, las ciencias sociales y la teoría literaria. De acuerdo con Cortina-Pérez y Andúgar Soto (2018), el objetivo principal en cuanto al aprendizaje de un idioma debe ser la competencia comunicativa; sin embargo para que esta se desarrolle adecuadamente es necesario que se preste especial atención a los contenidos lingüísticos, entre ellos los léxicos, gramaticales y discursivos. Además, tal como explica Di Tullio (2012, p. 8), la reflexión sobre el lenguaje plantea "[...] explorar los mecanismos productivos de la lengua, a partir del significado para llegar a los elementos formales en la producción o, en sentido inverso, en la comprensión". Como ya se ha mencionado, sería conveniente que en las 
clases de español como lengua extranjera la lectura de un texto literario no sea un pretexto para enseñar determinados conceptos gramaticales ni se centre en extraer contenidos de él. Pero sin dudas, es esperable que la lectura literaria desencadene la reflexión sobre el uso del lenguaje y se indague sobre la configuración discursiva; por ejemplo, un relato puede propiciar la reflexión sobre el uso de determinados tiempos verbales y los efectos de sentido que su uso generan en ese discurso en particular (XXX, 2018).

Finalmente, resta agregar que el texto literario puede concebirse como una forma de saber. En efecto, según la ya clásica obra de Iser (1976), la ficcionalización se entiende como un modo de conocimiento y de construcción de hipótesis sobre lo real. Por ello, leer literatura en otro idioma y producida en otro país es una forma particular de acceder a un patrimonio social y cultural específico, rico y diferente.

\section{La literatura infantil y juvenil argentina.}

\subsection{Un recorrido histórico}

La LIJ ha estado vinculada, desde sus orígenes, a la lectura escolar. Específicamente, en la Argentina la promulgación de la Ley 1420 de Educación Común, que implicó la ampliación del público lector, demandó la edición de libros escolares y literarios. En sentido, a fines del siglo XIX, se comenzó a conformar una serie de editoriales especializadas en libros de texto y literatura destinada a niños, como es el caso de Estrada, Losada y Kapelusz.

Para lograr una circulación exitosa en el ámbito escolar, la LIJ muchas veces ha cumplido una función ética y se le ha exigido ser transmisora de valores y moralejas. En efecto,

La literatura infantil, en sus inicios, sierva de la pedagogía y de la didáctica, se dirigía al niño escolar — que ya es un niño artificial—, de uniforme, mesurable según criterios meramente escolares basados en el rendimiento, en la conducta, en la capacidad de adecuarse al modelo escolar (RODARI, 1987, p.7).

Entonces, la maquinaria escolar ha transformado a la literatura en "recurso didáctico", depositario de enseñanzas y valores extracurriculares (Bombini, 1996). Así se fue consolidando una lectura escolarizada,

cristalizada en un listado de libros, que evitarían conflictos, temas tabús o dificultades, un canon disciplinado y ordenado en géneros, fragmentos y trozos selectos, actividades y reglas; a su vez, la tensión entre la obligatoriedad de la enseñanza y la gratuidad del goce y el encuentro placentero con el texto (CAÑóN Y HERMIDA, 2012, p. 37).

Este imaginario de la LIJ sujeta a objetivos primordialmente didácticos y moralizantes ha predominado con bríos durante las primeras seis décadas del siglo XX. Su circulación se produjo, tanto en libros de cuentos y novelas, como en libros de lectura -un subgénero de los libros didácticos que se usaba generalmente en la escuela primaria-, y se 
caracterizaba por presentar una serie de textos selectos. Entre los primeros escritores argentinos de LIJ se hallan Enrique Banchs, Álvaro Yunque, Conrado Nalé Roxlo, Enrique Wilde, Germán Berdiales, Marta Saloti y Constancio C. Vigil.

Por un lado, Enrique Banchs (1888-1968) tuvo a su cargo una página semanal de lecturas para niños en el diario La prensa de Buenos Aires, donde difundió su extensa producción para chicos, compilada actualmente en los volúmenes Para contar al hermanito y Cuentos para sonreír y pensar. En tanto que Álvaro Yunque (1889-1982) fue un prolífico escritor de relatos y poemas. Publicó Barcos de papel, Zancadillas, Los animales hablan, Jauja, Muchachos del Sur, La barra de Siete Ombúes, Ta-te-ti; Mocho y el espantapájaros; Nuestros muchachos; Niños de hoy; El amor sigue siendo niño; Laberinto Infantil; Las alas de la mariposa; Animalía y Cuentos con chicos. Por otro lado, Conrado Nalé Roxlo (1898-1971) es el autor de los clásicos La escuela de las hadas, Balada de Doña Rata, El gallo de la veleta y El grillo (1923).

Pionera en el estudio de la LIJ, Marta Saloti creó la cátedra de Literatura Infantil y Juvenil en 1960 en el Instituto Bernasconi y Summa Marta Salotti y fue directora de las colecciones de cuentos para niños El mirador, El balcón y La ventanita de Editorial Guadalupe. Si nos referimos a la obra de Germán Berdiales (1896-1975), esta fue predominantemente escolar. Escribió Las fiestas de mi escuelita (1924), Fábulas en acción (1927), Padrino (1929), El último castigo: cuentos para padres y maestros (1929), Fabulario (1933) y Maestros del idioma (1936).

Además, mencionaré a Constancio C. Vigil (1876-1954). Director de editorial Atlántida, fundó una serie de revistas, como Billiken (1919), la primera revista argentina para niños, que lamentable en la actualidad enfrenta una gran crisis económica que hace peligrar su continuidad. Por otra parte, Vigil escribió más de cincuenta libros de literatura destinados a niños que publicó en su editorial, como La reina de los pájaros, El bosque azul, La familia Conejola, Botón Tolón, La hormiguita viajera y El mono relojero (XXX, 2016). Si bien muchas de sus obras han sido consideradas clásicas, también fueron tildadas de "moralizantes" por los críticos y especialistas. Sin embargo, como di cuenta en un trabajo previo (XXX, en prensa), la identidad infantil se construye en su obra cimentada en la tensión entre autonomía y autoridad, entre las necesidades del niño y los mandatos del adulto. Vigil logró dar cuenta, así, de la heterogeneidad de intereses y los matices de la infancia. Modeló en sus textos un niño que debe ser, pero que también puede ser, una dicotomía que Vigil dejó plasmada en la literatura escolar y que sigue vigente hoy en día.

No obstante, a lo largo de estas décadas, el campo de la LIJ no estuvo exento de luchas ni tensiones. En efecto, lograron circular manifestaciones literarias de gran impacto artístico y cultural que supieron apartarse de la impronta moralista y didáctica. Algunas de estas obras han puesto el foco en la dimensión estética y desarrollaron temas alejados de los tópicos convencionales que circulaban en la época. Entre ellos, podemos mencionar a Horacio Quiroga, con su ya clásico Cuentos de la selva -que integra actualmente el canon de la escuela primaria en la Argentina-; José Sebastián Talló, quien en Las torres de Nuremberg de 1927 introdujo el juego de palabras, las onomatopeyas y las adivinanza en la poesía para niños y Manuel Mujica Láinez con su recordado cuento "El hombrecito del azulejo". Otro gran exponente de la LIJ es Javier Villafañe, titiritero, escritor de poesía y de teatro para niños, cuyo libro más emblemático es el Gallo Pinto de 1944. Fue uno de los primeros en incorporar la tradición oral en la literatura infantil argentina. 
Pero sin dudas es en la década de los 60, a partir de María Elena Walsh (MEW), que la LIJ se consolida como hecho estético. Según sostiene Origgi, MEW "logra jerarquizar el lenguaje creando material de juego lo más estético posible con el lenguaje más rico posible" (2012: 35). De esta forma, MEW planteó una revolución para la LIJ de una época en la que no se valoraba el placer de la lectura sino la producción de diversos aprendizajes. En efecto,

MEW va a oponer el discurso del disparate frente a los discursos escolares, cuya poesía era de las fábulas tradicionales, con su ideología moralizante o los poemas dedicados a los actos escolares, con una retórica hueca y un vocabulario alejado del infantil (ORIGGI, 2012: 35).

La propuesta estética iniciada por MEW, Laura Devetach, Gustavo Roldán, Graciela Montes y Elsa Bornemann fomentó el uso de la imaginación y la dimensión lúdica del lenguaje, y disminuyó la mirada protectora-educadora para dirigirse al niño lector.

Sin embargo y, como ya se explicó en XXX (2018), durante el período de la última dictadura militar, que abarcó los años 1976-1982, la censura llegó también a los libros infantiles, y varias obras, hoy clásicos de la LIJ, fueron prohibidas, como La torre de cubos, de Laura Devetach, y Un elefante ocupa mucho espacio, de Elsa Bornemann.

Con el advenimiento de la democracia en 1983, se produjo la apertura del canon escolar a textos de autores contemporáneos de la llamada nueva LIJ y, ya entrado el siglo XXI, se modificó el mapa editorial, que dejó de estar formado mayoritariamente por editoriales nacionales. Muchas de ellas fueron adquiridas por editoriales extranjeras y se fortalecieron los grupos editoriales multinacionales. Entre las editoriales actuales de LIJ se encuentran algunos grandes grupos como Penguin Random House, que cuenta con los sellos de Sudamericana y Alfaguara (recientemente adquirido a Santillana); Santillana, que posee el sello Loqueleo y Norma; Mac Millan que tiene en su haber Cántaro y Estrada, Urano, con Uranito, y el grupo Norma con su sello de LIJ homónimo. Por su parte, existen otras editoriales extranjeras más pequeñas que tienen su selo de LIJ, como SM, Edelvives, Edebé y Fondo de Cultura Económica (FCE). Según la investigación de Ruiz,

en la década reciente el sector que ha crecido más exponencialmente en la Argentina ha sido el de la LIJ. En efecto, según el informe de la Cámara Argentina de Publicaciones de febrero de $2017^{7}$, a pesar de la caída de ventas del rubro editorial general, la sección de libros infantiles y juveniles lleva más de seis años consecutivos de crecimiento y representa un $13 \%$ del mercado editorial argentino. Asimismo, los libros infantiles y juveniles alcanzan el $23 \%$ de la producción de libros editados por el sector editorial comercial (SEC) en 2016. (LUQUE, 2018, p. 44)

También, es necesario señalar que durante la última década se han creado diversos emprendimiento independientes de LIJ. Eso ha significado un verdadero boom comercial, ya que es el único sector del mercado editorial que ha crecido y expandido en las últimas décadas. Entre los sellos de LIJ independientes se encuentran Colihue, Unaluna, Amauta,

${ }^{7} \mathrm{El}$ informe puede consultarse online en el siguiente link: https://issuu.com/camaradellibro/docs/informe_de_producci_n_anual_2016_v 
Crecer Creando, Abran cancha, Libros del Eclipse, Calibroscopio, Galerna, Sigmar, Pequeño editor, La Bohemia. Libros del Náufrago y Riderchail, entre muchos otros.

Para ofrecer un listado de los escritores más reconocidos de la LIJ argentina, podemos mencionar a María Elena Walsh, Javier Villafañe, Elsa Bornemann, Laura Devetach, Gustavo Roldán, María Teresa Andruetto, María Cristina Ramos, Ema Wolf, Silvia Schujer, Graciela Montes, Graciela Cabal, Ricardo Mariño, Luis Pescetti, Liliana Bodoc, Esteban Valentino, Isol, Liliana Cinetto, Franco Vaccarini, Mario Méndez, José Luis María Pescetti, Martín Blasco, Andrea Ferrari, Sergio Aguirre, Paula Bombara y Antonio Santana, solo por citar algunos.

A lo largo de esta sección, quise mostrar parte de la historia y del presente de la LIJ. El objetivo fue ofrecer un recorrido por sus orígenes y dar a conocer los escritores y las editoriales más emblemáticas de la Argentina para acercar a los (futuros) profesores de español como lengua extranjera a este objeto de estudio con el fin de que puedan trazar sus propias trayectorias lectoras.

\subsection{La elección de la lectura}

En primer lugar, es necesario precisar algunos conceptos sobre la LIJ. De acuerdo con Andruetto (2008), el gran peligro que acecha a la LIJ es su categorización, pues este tipo de literatura se define en relación con sus destinatarios, es decir se presenta a priori como infantil o como juvenil. En este sentido, la autora advierte:

Lo que puede haber de 'para niños' o 'para jóvenes' en una obra debe ser secundario y venir por añadidura, porque el hueso de un texto capaz de gustar a lectores niños o jóvenes no proviene tanto de su adaptabilidad a un destinatario sino sobre todo de su calidad, y porque cuando hablamos de escritura de cualquier tema o género, el sustantivo es siempre más importante que el adjetivo. De todo lo que tiene que ver con la escritura, la especificidad de destinatario es lo primero que exige una mirada alerta, porque es justamente allí donde más fácilmente anidan razones morales, políticas y de mercado. (ANDRUETTO, 2008, en línea).

Atendiendo a este concepción, debemos saber que elegir textos de LIJ para abordar en las clases de español no implica que estos sean más fáciles de leer, porque su vocabulario sea más sencillo, porque sean breves o porque tengan muchas ilustraciones. Sin dudas, se trata de prejuicios que hay que desterrar. La decisión de elegir LIJ debe estar ligada a la calidad literaria de los textos que se escojan, al trabajo sensible que el escritor realiza sobre el lenguaje $\mathrm{y}$, por añadidura, porque constituye una forma particular de acceder a la lengua española y al patrimonio cultural argentino, en particular.

Como es sabido, un buen texto de LIJ es plurisignificativo, es decir, como toda literatura, está abierto a múltiples significados y se construye en cada lectura personal.

A partir de este encuadre, el objetivo de la presente propuesta es, en términos de Andruetto, concebir a la literatura sin adjetivos. La idea es valorar la LIJ como hecho estético y que, por ende, puede ser disfrutado por distintos tipos de lectores, niños, jóvenes o adultos. Entonces más que preguntarse ¿por qué leer LIJ en las clases de ELSE?, habría que plantearse ¿por qué no? 
En segundo lugar, me referiré a la selección y construcción del corpus. A la hora de encarar mi participación en el programa de la UFF, llevé a los encuentros presenciales libros impresos de distintos géneros, editoriales, autores y temas, con la intención de que los participantes pudieran familiarizarse con los materiales del mercado editorial argentino. Desde el extranjero, estos libros pueden adquirirse mediante librerías o plataformas electrónicas, pero esto implica un costo que no todos los estudiantes pueden afrontar. Por ello también trabajé con literatura on line, a la que se puede acceder en forma libre y gratuita. Se trata de material editado por el Ministerio de Educación de la Nación de Argentina y subido en formato PDF, libros digitales o audiolibros a diferentes sitios, como: http://www.conectate.gob.ar/, http://www.educ.ar/ y http://planlectura.educ.ar. También se puede hallar buena LIJ en http://www.imaginaria.com.ar. Estas herramientas constituyen una excelente opción para acceder a literatura de gran calidad en forma práctica y gratuita y poder distribuirla fácilmente entre los participantes.

Cabe aclarar que el Plan Nacional de Lectura Argentino, iniciado en 2009, articula tareas con todos los niveles educativos y con diversos programas del Ministerio de Educación. Entre los recursos que ofrece se destacan los talleres y capacitaciones de formación docente, la producción de material literario y pedagógico (RUIZ LUQUE, 2018). Si nos dirigimos al sitio http://planlectura.educ.ar y cliqueamos en la pestaña "Recursos. Recursos literarios", podemos hallar textos de amplia diversidad: infantil, juvenil, adultos, antologías, cuentos, poemas, obras de teatro, etc. También figuran "Recursos pedagógicos", con guías para los docentes, y "Recursos audiovisuales" con narraciones, entrevistas, ciclos literarios, etc.

A modo de ejemplo, para abordar en este trabajo, escogí un texto en formato impreso, pero que también puede descargarse en forma digital (PDF del texto más ilustraciones) ${ }^{8}$. Elegí "Mamá, ¿por qué nadie es como nosotros?" de Pescetti, por varios motivos: el renombre del autor, la calidad del texto (que cuenta con gran cantidad de recursos retóricos y poéticos) y la temática tan actual y común a diferentes culturas: la diversidad familiar. Como sostienen Cuesta y Frugoni, "la lectura literaria es una práctica sociocultural privilegiada para propiciar en los chicos la apropiación de diversos saberes, en tanto se manifiesta como una experiencia vital" (CUESTA Y FRUGONI, 2004, p. 14). Este texto fue abordado en uno de los encuentros de la UFF, cuyos destinatarios fueron futuros profesores de español como como lengua extranjera, pero las estrategias didácticas propuestas allí podrían ser adaptadas a otras instancias educativas, en diferentes grupos.

En suma, el valor estético y la relevancia cultural del texto, sumado a su accesibilidad, fueron las causas de su elección para analizar en este artículo.

\subsection{Mamá, ¿por qué nadie es como nosotros?}

8 Puede leerse y descargarse el texto completo del siguiente enlace: http://planlectura.educ.ar/wpcontent/uploads/2015/12/Mam\%C3\%A1-por-qu\%C3\%A9-nadie-es-como-nosotros-Luis-Mar\%C3\%ADaPescetti.pdf. 
Luego de leer un texto en la clase, ya sea en forma individual o grupal, no es conveniente imponer actividades. En efecto,

Lo importante es que el texto se disfrute y que el mediador esté atento a lo que la lectura genere. Un texto puede desencadenar risas, comentarios, preguntas, pero también silencios... Si se abre una charla para conversar sobre lo leído, esta puede ser pensada como un espacio para compartir emociones y enriquecer la lectura (XXX, 2018, p. 563).

El texto de Pescetti propuesto puede conducir a una charla sobre diferentes tópicos, como la familia, los estereotipos y la mirada de los otros. A continuación, muestro diferentes dimensiones que pueden tenerse en cuenta luego de leer el texto -si la situación y el grupo lo ameritan-. Cada docente elegirá qué aspecto abordar y mediante qué estrategias (actividades, proyectos, etc.) de acuerdo con cada experiencia aúlica.

\subsection{La temática: la familia}

En términos de de Certeau (2000), entendemos la lectura como una manera de participar activamente de la sociedad y la cultura. Guiada por dicha concepción, elegí un texto que pueda convocar y constituir un punto de encuentro con los lectores. Según ya comenté, el texto de Pescetti trata sobre la diversidad familiar y puede analizarse desde diferentes áreas: la sociología, el derecho, la antropología, etc.

Como sabemos, a lo largo de la historia el modelo de familia imperante en Occidente ha sido una estructura nuclear en donde la esposa y los hijos se subordinan al poder del padre y comparten el mismo techo. Esta imagen de familia es la que se ha percibido tradicionalmente como "normal" hasta el punto de ser naturalizada. No obstante, siempre existieron otros tipos de organización familiar, que fueron considerados "extraños" o "fuera de lo común", y hasta categorizados como "anormales" o "desvíos".

Por ello, es necesario tener en cuenta que, durante las últimas décadas, la concepción clásica de la familia se ha ido transformando y evolucionando en diferentes sentidos. Así, comenzaron a manifestarse y consolidarse diversos tipos de organización familiar: madres que trabajan fuera de la casa; padres que no lo hacen y se ocupan de las tareas del hogar; matrimonios que por razones laborales no comparten el mismo techo; matrimonios divorciados, con o sin pareja nueva, con hijos convivientes o no (que pueden conformar las denominadas "familias ensambladas"); madres solteras; padres divorciados con la tenencia de los hijos; parejas homosexuales con o sin hijos; parejas heterosexuales que eligen no tener hijos; abuelos u otros parientes que se hacen cargo del cuidado de los niños, etcétera.

\subsection{Concepciones sobre la familia}


Para los antropólogos, la familia es un fenómeno universal que se manifiesta en todas las sociedades. Es posible definirla como un grupo nuclear cimentado en la unión duradera y socialmente aprobada de un hombre, una mujer y sus hijos, que conviven en la misma casa.

Desde una perspectiva histórica, podemos observar cómo se ha modificado la constitución familiar. Según Valeria Paván (2005), en el derecho romano es el pater quien se designa como padre por adopción (la filiación biológica no se tiene en cuenta), mientras que el cristianismo impone la paternidad biológica y solo es declarado padre quien se somete a la legitimidad sagrada del matrimonio. Entre los siglos XVIII y mediados del XX, recién se consolida el modelo de familia moderno como espacio de la lógica afectiva, fundada en el amor romántico, es decir el matrimonio cambia de naturaleza: ya no es meramente un mandato de Dios, sino un contrato libremente consentido entre los cónyuges. Ya, a lo largo del siglo XIX, la autoridad paterna se revaloriza a la vez que se fragmenta, pues el marido tiene obligaciones morales con su esposa e hijos y puede perder el derecho a ser padre.

En el siglo XX, a partir de los 60, surge la familia contemporánea o posmoderna, en donde el modelo patriarcal tradicional entra en crisis y comienza a convivir con nuevas situaciones: divorcios, separaciones y nuevas nupcias. Desde entonces hasta la actualidad se produce y se consolida "una creciente multiplicidad de formas de familia y convivencia" (JELÍN, 1998, p. 18). Estos cambios podrían deberse a dos razones fundamentales: 1) las actividades actuales obligan a los sujetos a desplazarse de un lugar a otro durante su vida laboral y esas transferencias generan un aumento de las relaciones, y también de los conflictos; y 2) el avance de las comunicaciones ha favorecido la universalización de las pautas familiares.

En este sentido, todos estos elementos políticos, sociales, jurídicos y económicos han influido en el cambio de la representación de la familia ${ }^{9}$ al menos en el mundo occidental. Por ello es un tema que nos atraviesa más allá de la nacionalidad y la lengua que hablemos.

\subsection{La configuración discursiva de la familia y los estereotipos}

En este apartado, propongo la reflexión sobre algunos aspectos lingüísticos del texto a nivel microdiscursivo, como pronombres, discursos referidos y conectores, que contribuyen a la producción de ciertos efectos de lectura. No pretendo que se apliquen todos estos elementos en la clase, sino que funcionen simplemente como material de guía para el profesor.

El texto trata sobre la multiplicidad de formas de organización familiar así como de diferentes estilos de vida. Se presentan a través de secuencias descriptivas (construidas, por ejemplo, con el verbo es: "El papá de Juan es ingeniero en computación” en 1) y secuencias argumentativas que, generalmente, refutan esa descripción por considerarla

\footnotetext{
${ }^{9}$ También es posible analizar otros textos argentinos de LIJ que tratan sobre la familia y realizar un abordaje comparativo. Se sugieren, entre otros: Bornemann, E. (1975) (2004). Sobre la falda en Un elefante ocupa mucho espacio, Alfaguara, Buenos Aires; Cabal, G.B. (1988) (2005) "La señora Planchita". En La señora Planchita y un cuento de hadas pero no tanto, Sudamericana, Buenos Aires; Montes, G. (1989) La familia de la soga, Colihue, Buenos Aires y Wolf, E. (1992) (2004) Fámili, Sudamericana, Buenos Aires.
} 
extraña; en (1), Joshua no entiende cómo Juan y su familia pueden vivir mudándose toda la vida (ver subrayados) ${ }^{10}$.

(1) El papá de Juan es ingeniero en computación, pero heredó de su familia un camión con el que hace mudanzas (si no son muy grandes), y ellos mismos han cambiado de barrio siete veces desde que él nació. Juan chatea con un amigo que conoció por Internet. Vive en México y se llama Joshua. Él no entiende cómo Juan y su familia pueden vivir mudándose toda la vida.

Por un lado, un interrogante recurrente, enunciado por distintos personajes, funciona como eje vertebral del relato "Mamá, ¿por qué nadie es como nosotros?", que además titula la obra. A través de esta pregunta en primera persona se plantean distintos tipos de familia y se pone en primer plano la diversidad, como categoría central de caracterización del núcleo familiar en la actualidad. La repetición de esa frase en la voz de cada personaje/niño evidencia la singularidad de cada familia y a la vez evidencia la diversidad. Como se observa, en la conformación de la familia contemporánea coexisten múltiples nacionalidades y lenguas, diferentes razas, distintas religiones, profesiones, recomposiciones familiares (familias ensambladas, diversas formas de vida, y distintos intereses y gustos personales). Al respecto, puede proponerse en la clase la reflexión acerca del valor que tiene el pronombre personal en esta frase ("nosotros") que se actualiza en cada enunciado y, por lo tanto, corresponde a diferentes referentes.

Por otra parte, en el relato, la mayoría de los aspectos de la heterogeneidad familiar son percibidos como extraños e, incluso, son juzgados o reprobados por los mismos personajes/chicos. En el caso de Miguel (mamá judía y papá católico), "su amiga, Teresa, le dice que tendrían que elegir, porque nadie puede tener dos fines de año en un mismo año". Es decir que el texto plantea que los diversos modelos de familia pueden generar cierto extrañamiento o rechazo, en tanto se está percibiendo a un "otro" diferente. En ellos, opera la idea del preconcepto y del estereotipo. Recordemos que el estereotipo en términos de Amossy y Herschberg se define como "la visión que nos hacemos de un grupo es el resultado de un contacto repetido con representaciones enteramente construidas o bien filtradas por el discurso de los medios. El estereotipo sería principalmente resultado de un aprendizaje social" (AMOSSY y HERSCHBERG, 2015: 41). En este sentido, Amossy y Herschberg agregan: "lo que percibimos está moldeado de entrada por las imágenes colectivas que tenemos incorporadas en nuestra mente" $(2015$, p. 41)

Así, el texto pone en escena diferentes estereotipos de familia y las voces de los personajes los exhiben, afirmándolos o deconstruyéndolos. En este sentido, en la clase de ELSE podría analizarse cómo los discursos directos (como la pregunta que titula la obra) y los indirectos manifiestan preconceptos o estereotipos. Con relación a ello, observamos que un narrador omnisciente presenta las diferentes voces de niños que construyen la narración. Estas voces se vehiculizan mediante formas de heterogeneidad mostrada marcada (Authier-Revuz, 1984) ${ }^{11}$, en las que la presencia del otro se distingue unívocamente

\footnotetext{
${ }^{10}$ Los subrayados en los ejemplos me pertenecen y los utilizo para señalar el fragmento analizado.

11 Dentro del enfoque polifónico-argumentativo, Authier-Revuz (1984) distingue dos grandes heterogeneidades enunciativas: la constitutiva y la mostrada. La primera pone de manifiesto que el discurso, a pesar de que el sujeto tenga la pretensión de ser fuente autónoma del sentido, es constituido por otros
} 
mediante determinados recursos lingüísticos, como el discurso directo, marcado por la presencia de comillas.

En los siguientes ejemplos, el discurso directo evidencia la extrañeza que sienten los personajes frente a las diferentes características de las otras familias (ver subrayados). Se producen así cadenas de discursos directos estereotipados. En (2), se pone en escena la voz de Flavia que cuestiona la forma de hablar de la familia de Joshua; en (3) se exhibe la extrañeza que siente Raúl por la multinacionalidad de la familia de Flavia y en (4) Esteban cuestiona aspectos religiosos de la familia de Raúl.

(2) La mamá de Joshua es peruana, el papá es estadounidense, y él nació en México. Flavia, quien los conoció en un viaje, le pregunta a su mamá: “¿Por qué ellos no hablan como nosotros?"

(3) El papá y la mamá de Flavia son brasileros viven en Brasil, pero sus abuelos maternos son una señora danesa casada con un señor brasilero. Ellos viven en Venezuela. Sus abuelos paternos son un señor italiano casado con una señora inglesa. Éstos viven en Brasil. Cierta vez ganaron un premio en un concurso de televisión. Raúl los vio desde su propio país y, al saber cómo estaba compuesta esa familia, le comentó a su mamá: "¿Qué raros son!”.

(4) Los padres de Raúl, son colombianos. El papá es pastor protestante, y Raúl, a veces, juega en el templo. En la escuela tenía un amigo llamado Esteban, quien siempre le preguntaba: "Raúl, ¿qué se siente tener un papá medio cura?".

Así, al localizar y exhibir un elemento heterogéneo (el discurso ajeno), mediante el entrecomillado, el narrador toma distancia y lo exhibe como producto de un otro.

Pero también el texto analizado presenta formas de heterogeneidad mostrada no marcada, en donde la presencia del otro aparece sin marcas explícitas, como el discurso indirecto e indirecto libre. Como vemos en (5), el preconcepto sobre lo raro que le sonaba a Miguel que toda la familia de Esteban se hubiera mudado solo porque el papá quería estudiar se vehiculiza mediante el discurso indirecto (“dijo que...").

(5) Esteban se fue a vivir con su familia a Canadá, por una beca que consiguió el padre. Sus abuelos son polacos, originarios de un pueblo que ya no existe, pues desapareció durante la guerra. Se escribe con un amigo que se llama Miguel, y en una carta éste le dijo que le sonaba extraño que toda la familia se hubiera mudado sólo porque el papá quería estudiar.

También, es interesante analizar los efectos de sentido de los segmentos que se encuentran entre paréntesis. Si bien la información entre paréntesis suele incorporar aclaraciones o datos accesorios, en (6), (7) y (8) se incluyen contraargumentaciones

discursos; la segunda altera la unicidad aparente del discurso al incorporar otras voces con señales explícitas o no. Dentro de este último grupo, se distinguen las formas no marcadas, en donde la presencia del otro aparece sin marcas explícitas, como, por ejemplo, el discurso indirecto libre, la ironía y la imitación; y las formas marcadas, en las que la presencia del otro se distingue unívocamente mediante determinados recursos lingüísticos: inserto en el hilo de los discursos preexistentes, el yo delimita las zonas de contacto que le devuelven la ilusión de ser dueño de las palabras. 
introducidas mediante conectores adversativos (pero en 6 y 7) y concesivos (aunque en 8) que aportan nuevos datos y erosionan los preconceptos establecidos. Respecto del uso del pero, este restringe, contradice u objeta lo dicho en la primera proposición y la dirección argumentativa se centra en el segundo elemento, que funciona a modo de conclusión. Por ejemplo, alguien puede pertenecer a una religión pero no creer en nada (6), o haber nacido en Perú pero ser, en realidad, japonés (7).

En el caso de (8), el conector aunque introduce una concesión: "Los papás de Alberto están separados aunque vivan en la misma ciudad". Con respecto a este último caso, Anscombre y Ducrot (1984) puntualizan que la concesión supone una "contraargumentación" (ANSCOMBRE y DUCROT, 1984), pues en ella se reconoce la validez del argumento presentado por aunque hacia una determinada conclusión ("están separados/alejados"), pero se concluye de modo contrario ("viven en la misma ciudad"). De ahí deviene que aunque como conector contraargumentativo vincula dos miembros del discurso de tal modo que uno se presenta como supresor o atenuador de alguna conclusión que se pudiera obtener del otro (PORTOLÉS, 2007). Es decir, el preconcepto podría ser que los padres viven en ciudades lejanas por estar separados, se objeta y se reemplaza por la proposición: viven en la misma ciudad/mismo espacio.

(6) La mamá de Yahir es musulmana, el papá de Teo es católico (pero la mamá dice que no cree en nada).

(7) La mamá de Mirta trabaja en un supermercado, la de Tomás es gerente en un banco. El papá de Raulito es negro, y su mamá es blanca; los papás de Iñaki son blancos, los papás de Sushiro son japoneses (pero nacieron en Perú).

(8) Los papás de Alberto son mexicanos, pero están separados (aunque viven en la misma ciudad).

Finalmente, es interesante, analizar también cómo se presenta la diversidad en el texto a partir de las contraposiciones ligadas con los conectores adversativos. Observemos el valor de pero en (9) y (10).

(9) Al papá de Eduardo le encantan los deportes, igual que a la mamá de Inés, pero al papá de Ignacio le gusta relajarse viendo la tele, mientras toma una cerveza.

(10) La mamá de Eugenio odia el fútbol, pero a la mamá de Coqui le encanta ir a la cancha.

En (9), el pero marca la contraposición entre dos formas distintas de disfrute, pero sin marcar que una es "mejor" que otra. En (10) sucede algo similar, pues se contrapone el odio por el fútbol de la mamá de Eugenio al gusto por ir a la cancha de la mamá de Coqui. Vemos que en ambos casos el conector restringe lo dicho en la primera proposición por la segunda. El efecto de sentido logrado tiene que ver con que no se objetan los diferentes gustos o preferencias, si no que se los presentan marcando solamente su contraposición; no hay juicio de valor.

A partir de lo desarrollado hasta aquí, he intentado mostrar una forma de abordar el texto de español prestando atención a la materialidad lingüística. Pensar sobre estos 
recursos (conectores, discursos referidos, pronombres, etc.) permite reflexionar acerca de cómo se construyen determinados efectos de sentido en español.

\section{A modo de conclusión}

En el presente artículo mostré la relevancia de leer textos literarios en las clases de ELSE y profundicé los distintos aspectos didácticos implicados, como el enfoque a adoptar, la elección del material y la finalidad de lectura.

Primero expliqué la importancia de abordar la literatura desde un enfoque multidisciplinario, haciendo foco en el disfrute de la lectura así como en la reflexión sobre el lenguaje. Luego y con el propósito de acercar a los (futuros) profesores a la LIJ argentina y plantear su abordaje en las clases de ELSE, tracé un recorrido por el campo e indagué sobre algunos criterios a tener en cuenta a la hora de elegir textos. Entre ellos destaqué el valor estético y la relevancia cultural de los textos, sumado a su accesibilidad.

Para ejemplificar la propuesta, seleccioné el texto de LIJ "Mamá, ¿por qué nadie es como nosotros?", del escritor argentino Luis María Pescetti, que puede encontrarse en tres ediciones -dos impresas y una digital, publicada está ultima por el Ministerio de Educación, Ciencia y Tecnología de Argentina- y que trata sobre los diferentes tipos de familia.

Como he mostrado en el análisis, las representaciones de familia del relato se construyen a partir de la fragmentación, la diversidad y la multiplicidad; dan cuenta de un estado nuevo de cosas basado en la consolidación de distintos tipos de familia no tradicionales. Un enfoque multidisciplinario como el aquí propuesto dio cuenta de que este texto de LIJ puede acercar a los estudiantes a distintas maneras de entender y percibir la familia, sus cambios, su diversidad y, paradójicamente, su singularidad. Asimismo, el abordaje reveló que a través de la reflexión sobre el lenguaje -alejada del enfoque contenidista y meramente gramatical- los alumnos pueden analizar los efectos discursivos y descubrir las diversas posibilidades de construcción de significados en el texto. Apelando a Petit (2001): "La lectura nos abre hacia otro lugar, donde nos decimos, donde elaboramos nuestra historia apoyándonos en fragmentos de relatos, en imágenes, en frases escritas por otros". Sin dudas, la construcción de la propia historia, de la identidad y del camino lector también puede realizarse en las clases de español a través de textos de LIJ, poniendo en escena "las identidades socioculturales de los lectores y de los conocimientos que ya poseen y que se disponen a poseer a partir del texto que se les presenta y de la mediación del docente que los acompaña" (FRUGONI Y CUESTA, 2004, p. 12). Se trata de un proceso complejo, que permite ampliar el horizonte cultural y construir nuevas subjetividades a partir de distintos conocimientos sobre una lengua y una literatura extranjeras.

\section{Referencias}

AMOSSY, R., HERSCHBERG, A. Estereotipos y clichés. Eudeba: Buenos Aires, 2015. 
ANDRUETTO, M. T. Hacia una literatura sin adjetivos. Disponible en: <http://www.imaginaria.com.ar/2008/11/hacia-una-literatura-sin-adjetivos/,> Acceso en: 02 dic. 2018.

ANSCOMBRE, J.C.; DUCROT, O. L'argumentation dans la langue. Bruselas: Pierre Mardaga Éditeur, 1984.

AUTHIER-REVUZ, J. Hétérogénéité(s) énonciative(s). Langages, 73, pp. 98-111, 1984. Ces mots qui ne vont pas de soi. Boucles réflexives et non-cö̈ncidences du dire.

París: Larousse, 1995

BOMBINI, G. Didáctica de la literatura y teoría : Apuntes sobre la historia de una deuda. Orbis Tertius, 1996 1(2-3). Disponible en: http://www.orbistertius.unlp.edu.ar/ Acceso en: 02 enero 2018

CAÑÓN, M. Y HERMIDA, C. La literatura en la escuela primaria. Más allá de las tareas. Buenos Aires-México: Ediciones Novedades Educativas, 2012.

CASTRO, M. E.; CONTRERAS, M. Á. ¿Para qué sirve la literatura en una clase de español? [en línea]. II Congreso Internacional de Literatura y Cultura Españolas Contemporáneas, 3 al 5 de octubre de 2011, La Plata, Argentina. Diálogos Transatlánticos. En Memoria Académica. Disponible en:

http://www.memoria.fahce.unlp.edu.ar/trab_eventos/ev.2860/ev.2860.pdf

CORTINA-PÉREZ, B y ANDUGAR SOTO, A. Didáctica de la lengua extranjera en educación infantil. Madrid: Pirámide, 2018.

CUESTA, C. y FRUGONI, S. Práctica sociocultural privilegiada para propiciar en los chicos la apropiación de diversos saberes. Buenos Aires: Ministro de Educación, Ciencia y Tecnología, 2004.

DE CERTEAU, M. La invención de lo cotidiano. I Artes de hacer. México: Instituto

DI TULLIO, Á. Reflexiones sobre el lenguaje: el lugar de la gramática en la escuela. Disponible en: http://museo.bn.gov.ar/media/page/di-tullio-angela-reflexiones-sobre-la$\begin{array}{lllll}\text { lengua.pdf } & \text { Acceso } & \text { en: } & 02 & \text { dic. }\end{array}$ http://www.memoria.fahce.unlp.edu.ar/trab_eventos/ev.2860/ev.2860.pdf

JELÍN, E. Pan y afectos. La transformación de las familias. Buenos Aires: Fondo de Cultura Económica, 1998.

LÓPEZ PRATS, E. El texto literario en el aula de Español como lengua extranjera. Propuesta de programación didáctica: Últimas tardes con teresa, de Juan Marsé. Tesis del máster de formación de profesores de español como lengua extranjera. Girona: Universitat de Girona, 2009. 
MENDOZA, A. El intertexto lector. El espacio de encuentro de las aportaciones del texto con las del lector. Cuenca: Universidad de Castilla, La Mancha, 2001.

ORIGGI, A. María Elena Walsh o la coherencia del disparate. Buenos Aires: AALIJ, 2012.

PAVÁN, V. Familia: una perspectiva histórica. En Novedades Educativas 177, Buenos Aires, 2005.

PETIT, M. Lecturas: del espacio íntimo al espacio público. México: Fondo de Cultura Económica, 2001.

PORTOLÉS, J. Marcadores del discurso. Barcelona: Ariel, 2007.

RODARI, G. La imaginación en la literatura infantil. Piedra Libre, Año 1, No 2. Córdoba: CEDILIJ, septiembre de 1987; págs. 4-13), 1987.

RUIZ LUQUE, M. Estrategias para la promoción de la lectura en el campo de la literatura infantil y juvenil. El caso de Loqueleo. Buenos Aires: Ciencias de la Comunicación, Facultad de Ciencias Sociales. Universidad de Buenos Aires. Tesina de grado, 2018.

XXX. Aprendiendo a ser niño. La configuración discursiva de la identidad infantil en un libro de lectura argentino. En Fernández Ulloa, T. (comp). La identidad en el mundo hispano. Igualdades y desigualdades en los siglos XIX, XX y XXI a través de diversos textos. Vigo: Editorial Academia del Hispanismo. En prensa.

Constancio C. Vigil. Editores y editoriales iberoamericanas (siglos XIX-XXI). Madrid: Biblioteca Virtual Miguel de Cervantes. 2016. Disponible en: http://bvmc.pre.cervantesvirtual.com/portales/editores_editoriales_iberoamericanos/

La literatura infantil y juvenil y el discurso pedagógico en las clases de español como lengua extranjera. Reflexiones en torno a la práctica docente. En ADRIANA ORTEGA CLÍMACO, ISIS MILREU Y RAQUEL DA SILVA ORTEGA (coord.). $O$ ensino de literatura hispânica: reflexões sobre a didática de ensino de literatura estrangeira. Editora da Universidade Federal de Campina Grande - EDUFCG y Universidade Federal de Campina Grande - UFCG, Brasil. 2018, pp. 551-577.

\section{Texto analizado}

PESCETTI, L. M. Mamá, ¿por qué nadie es como nosotros. En Nadie te creería.Alfaguara: Buenos Aires, 2005.

Recebido em 19 de fevereiro de 2019

Aceito em 27 de abril de 2019 